Asian J. Med. Biol. Res. 2020, 6 (3), 587-593; doi: 10.3329/ajmbr.v6i3.49812

\author{
Asian Journal of \\ Medical and Biological Research \\ ISSN 2411-4472 (Print) 2412-5571 (Online) \\ www.ebupress.com/journal/ajmbr
}

\title{
Article \\ Knowledge on safe blood transfusion practice of senior staff nurses working in tertiary hospital
}

\author{
Safarer Nessa ${ }^{1 *}$, M.H Faruquee ${ }^{2}$, Nawzia Yasmin ${ }^{3}$ and Munir Ahmed ${ }^{4}$ \\ ${ }^{1}$ Senior Staff Nurse, Dhaka Medical College Hospital, Dhaka, Bangladesh \\ ${ }^{2}$ Department of Occupational and Environmental Health, Bangladesh University of Health Sciences \\ ${ }^{3}$ Department of Public Health, State University of Bangladesh \\ ${ }^{4}$ Integrated Farm Management Component (IFMC-II), DAE-DANIDA, Khamarbari, Farmgate, Dhaka, \\ Bangladesh
}

Corresponding author: Safarer Nessa, Senior Staff Nurse, Dhaka Medical College Hospital, Dhaka, Bangladesh. E-mail: safarer.nessa73@yahoo.com

Received: 06 September 2020/Accepted: 27 September 2020/ Published: 30 September 2020

\begin{abstract}
Transfusion of blood saves life. An error in blood transfusion, at the same time, takes life. A cross sectional study was carried out for assessing the knowledge and practice on blood transfusion among the senior staff nurses using a structured questionnaire through face to face interview in Dhaka Medical College Hospital $(\mathrm{DMCH})$. Among the about half of the respondents (54.8\%)\% were in the age group above 40 consisting $97.6 \%$ of female where $98 \%$ were married.

By professional education $79 \%$ had Diploma in nursing and midwifery and $16.9 \%$ had graduation in nursing. This study revealed that the respondents could mentioned the name of screening tests as HBsAg (65.3\%), HIV (58.1\%), VDRL (53.2\%), HBV (23.4\%) and HBC (7.3\%). Things to be checked and things to be considered also evaluated among the respondent and found responsive results. This study revealed that among the respondents $57 \%$ had moderate knowledge on blood transfusion, $41 \%$ good knowledge and only $2 \%$ had poor knowledge. There is an association between knowledge level on blood transfusion and year of service. This association is statistically not significant having $\mathrm{p}$ value 0.074 . Among the respondents almost $48.4 \%$ stated transfuse screened blood as a preventive measure to fix problems regarding blood transfusion. Around 5.6\% of the respondents mentioned maintaining proper system of blood transfusion as a measure. A few respondents (4.0\%) said that difficulties due to blood transfusion can be prevented by controlling blood transfusion related side effects. The nurses practice self-protection of them and patient's protection during blood transfusion. There is needed of proper training on blood transfusion for prevention of complication in the patient as well as for the nurses themselves.
\end{abstract}

Keywords: Blood transfusion, senior staff nurses, hospital, Knowledge

\section{Introduction}

Transfusion of blood saves life. An error in blood transfusion, at the same time, takes life. Blood samples can be autologous, in which the patient's own blood is collected before surgery for possible use during or after surgery or allogenic, in which the blood is collected from donors. Clinical demand for blood is perennial and transfusion errors are accountable (Stainsby et al., 2006; Sackett et al., 2000). This accountability of transfusion errors comes to light with the numerous reports on total blood transfusion errors. The discovery that HIV could be transmitted by blood transfusion in 1982 has given rise to strict regulations on blood donation and the exercise of professional judgment (NMC, 2005).

Nurses being responsible for the final bedside check before transfusion, have the final opportunity to prevent a mistransfusion (Mole et al., 2007). Blood products most often transfused by nurses include packed red blood cells, fresh frozen plasma, and platelets (Simmons, 2003). An understanding and 
knowledge of the pathophysiology of transfusion reactions, symptoms and treatment is essential to safely administer and monitor transfusions (Labovich, 1997). A Failure Mode and Effect Analysis (FMEA) on the blood transfusion process to reduce the risk of problems inherent in the procedure has been developed recently to aid nurse decision making in the transfusion process (Burgmeier, 2002). Measures have been developed to analyze results and FMEA has been a valuable tool for error-trapping in the blood transfusion process. Transfusion error, resulting in the patient receiving the incorrect blood component, remains the largest risk related to transfusion. Nurses can increase compliance in high-risk areas of the transfusion process and reduce the potential for errors by developing accessible blood transfusion policies, auditable performance standards and training, and educational initiatives (Gray et al., 2005). A Study to assess the effect of a simple intervention in the form of a tag on blood bags positioned in such a way that the nurses required to remove the tag to spike the unit reminding nurses to check the patient's wristband has shown that such a simple intervention is ineffective and there is a need for more stringent practice guidelines for the nurses. Recently published guidelines highlight that most serious transfusion complications occur within the first fifteen minutes of transfusion and a close monitoring has been recommended before and fifteen minutes after commencement of each unit of blood (Rowe, 2000). The guidelines also recommend careful monitoring in the areas of sample collection, pre-administration checking to avoid adverse reactions (Hainsworth, 2004).

A nurse, by profession has opportunities to establish policies and procedures, design nursing practices, and educate staff to help avoid blood transfusion errors. There is an urgent need of training programmes in nursing units that educate nurses on blood transfusion risk reduction, latest safety guidelines, and nurse interventions.

Therefore, this study is an attempt to assess the knowledge level on blood transfusion of nurses regarding transmitted infection, complication, caring and management of this kind of patient. The findings of this study provide valuable information for further in-depth as well as interventional study. The health planners may get guideline to formulate appropriate intervention strategies to raise the knowledge among the nurses.

\section{Materials and Methods}

\subsection{Type, place and duration of study:}

This a cross sectional descriptive type of study to assess knowledge and practice on blood transfusion among the Senior Staff Nurses working on medical, surgical and Gynae word of Dhaka Medical College Hospital during May to August 2011.

\subsection{Study population}

Senior Staff Nurses who are serving the Dhaka Medical College Hospital, Dhaka-1205 in the area of medical, surgical and Gynae ward.

\subsection{Selection criteria}

Inclusion Criteria: All Registered Nurses working in medical, surgical and Gynae ward

Exclusion Criteria: Senior Staff Nurse serving in other departments where blood transfusion is less available, Operation theatre and Emergency department where nurses are time consuming.

\subsection{Sample size}

Sample size for the study was decided by following equation:

We know,

$\frac{\mathrm{n}=\mathrm{Z}^{2} \mathrm{Xpq}}{\mathrm{d}^{2}}$

Here,

$\mathrm{n}=$ Desired sample size

$\mathrm{z}=\mathrm{value}$ of standard normal distribution as given level of significant, usually considered 1.96 at $95 \%$ confidence interval $(\mathrm{CI})$

$\mathrm{p}=$ Proportion of target population or prevalence of satisfactory knowledge on blood transfusion, $51.60 \%(0.51)^{14}$

$\mathrm{q}=1-\mathrm{p}$ therefore, $1-0.5=(0.5)$

$\mathrm{d}=$ Allowable error in the study 5\% (0.05)

As per equation, sample size $(n)=(1.96) 2 * 0.5 /(0.05) 2=384.16(384)$

All the nurses of medical, surgical and gynae wards were approached and only 124 were agreed to participate in the study. 


\subsection{Sampling technique}

Purposive sampling technique (All the nurses of medical, surgical and Gynae wards were approached to participate in the study and those to agreed were included in the study up to the desired sample size).

\subsection{Data collection instrument}

An interview scheduled in Bangla was used to collect the data. After pretesting at the Infectious Disease Hospital (IDH) Mohakhali, Dhaka, it was reviewed and necessary correction was made.

\subsection{Data collection}

Data were collected by face to face interview and practice parts will be observed by the researcher.

\subsection{Data analysis}

After completion of data collection these were checked, verified and edited for consisting to reduce error. Descriptive and statistical methods were used in analyzing the data. The important variable were considered and analyzed to fulfill the objective of the study. The results were calculated from tabulated column.

\subsection{Ethical issue}

Permission from ethical review committee of State University of Bangladesh was taken and informed consent was obtained prior to the interview.

\section{Results}

\subsection{Socio-demographic and economic characteristics}

Among the respondents highest number was found in the age group of above 40 years $(54.8 \%)$, followed by in age group 36-40 years (35.5) and lowest (0.8\%) was in above 26-30years. In this study, the number of female far outweighed the number of male. Out of total 124 respondents $97.6 \%$ were female and only $2.4 \%$ were male. Out of 124 respondents, $98 \%$ were married whereas only $2 \%$ were unmarried. Most of the respondents belonged to Islam (80\%); number of Hindu respondents stood at $17 \%$ and the number of Christian respondents was $3 \%$. About $50.8 \%$ of the respondents had job experience ranging from 11 to 15 years. This was closely followed by the respondents having job experience over 20 years was $34.7 \%$. The number of respondents who had job experience between 6 and 10 years stood at 11.3\% whereas this figure accounted for only $3.2 \%$ for respondents who worked for 16 to 20 years. Details results are shown in Figure 1.

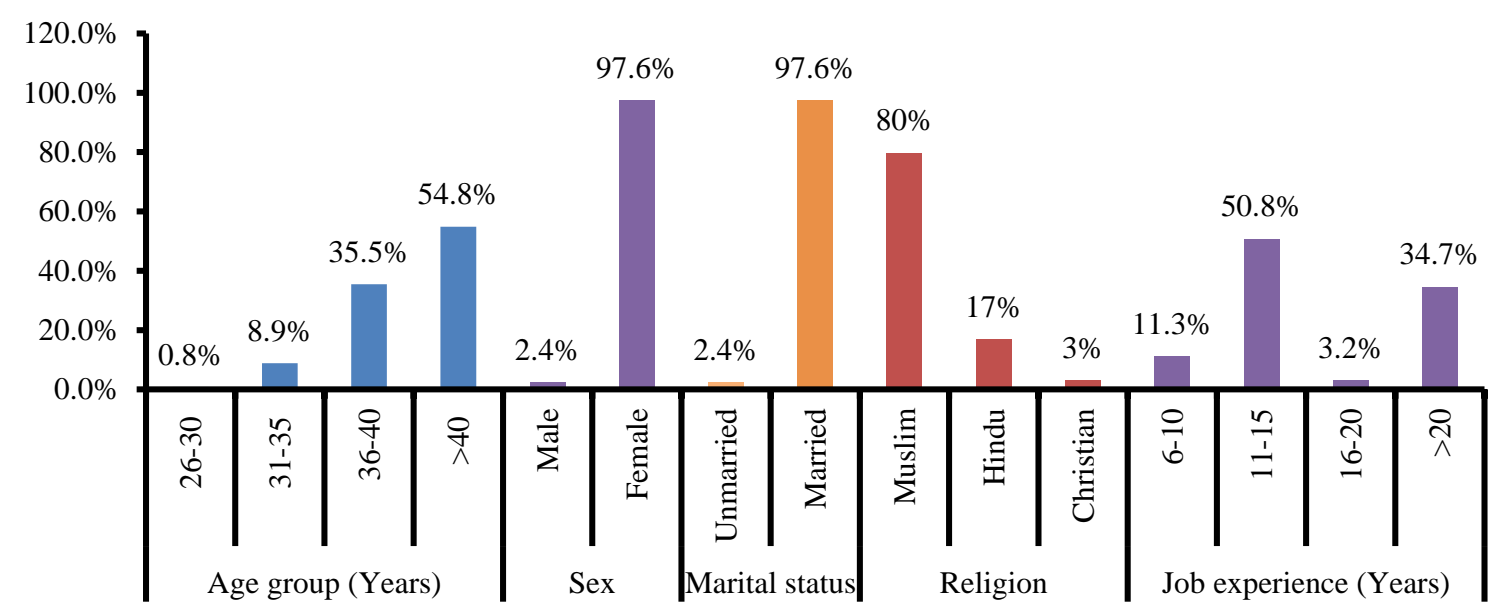

Figure 1. Distribution of different socio-demographic factors $(\mathbf{n}=124)$.

\subsection{Distribution of the respondents by professional education}

In this study $100 \%$ of the respondents had diploma in nursing. This was closely followed by diploma in midwifery at which was $97.6 \%$. The number of respondents having B.Sc in nursing stood at $21 \%$. Only $2.4 \%$ respondent had professional education equivalent to midwifery. 
3.3. Training on blood transfusion $(n=124)$

Out of 124 respondents 59\% have training on blood transfusion and rest of (41\%) no training on blood transfusion (Figure 2).

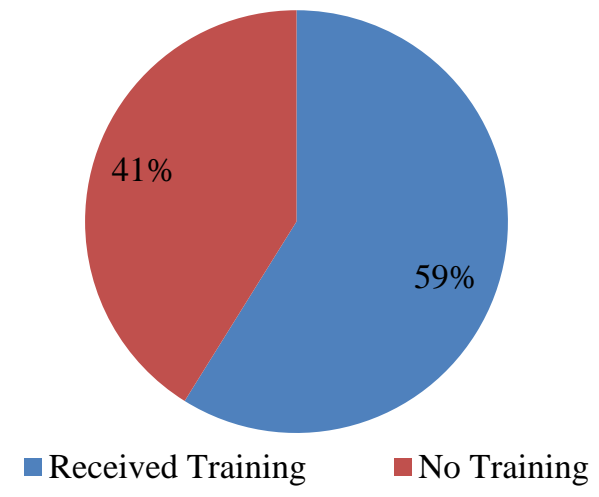

Figure 2. Training on blood transfusion.

About $32.3 \%$ of the respondents got training for six months before (Table 1). Again $18.5 \%$ of the respondents got training for 1 year before and a further $8.1 \%$ got training for 2 years before (Table 1).

Table 1. Time of training of respondent on blood transfusion $(n=73)$.

\begin{tabular}{lll}
\hline Training Period & Frequency $(\mathbf{n})$ & Percentage $(\%)$ \\
\hline 6 month ago & 40 & 32.3 \\
1 year ago & 23 & 18.5 \\
2 Years ago & 10 & 8.1 \\
Total & $\mathbf{7 3}$ & $\mathbf{1 0 0 . 0}$ \\
\hline
\end{tabular}

A large number of respondents mentioning HBsAg comprised 65.3\%, another 53.2\% mentioned VDRL in this regard. In contrast, only about $7.3 \%$ stated that HBC can be seen through screening. Among the respondents, almost $96.0 \%$ said that blood group was checked on bags before blood is given to patients. A further $39.5 \%$ mentioned that screening result is needed to consider before blood transfusion. However, $0.8 \%$ did not say anything in this regard. A significant number of the respondents comprising almost $88.7 \%$ mentioned that whether shivering is present or not is important to notice during blood transfusion. This was closely followed by skin rash at $83.1 \%$. Among the respondents $89.5 .1 \%$ of the respondents mentioned that HIV and $90.3 \%$ Hepatitis B are the diseases that spread through blood. Details results are shown in Figure 3.

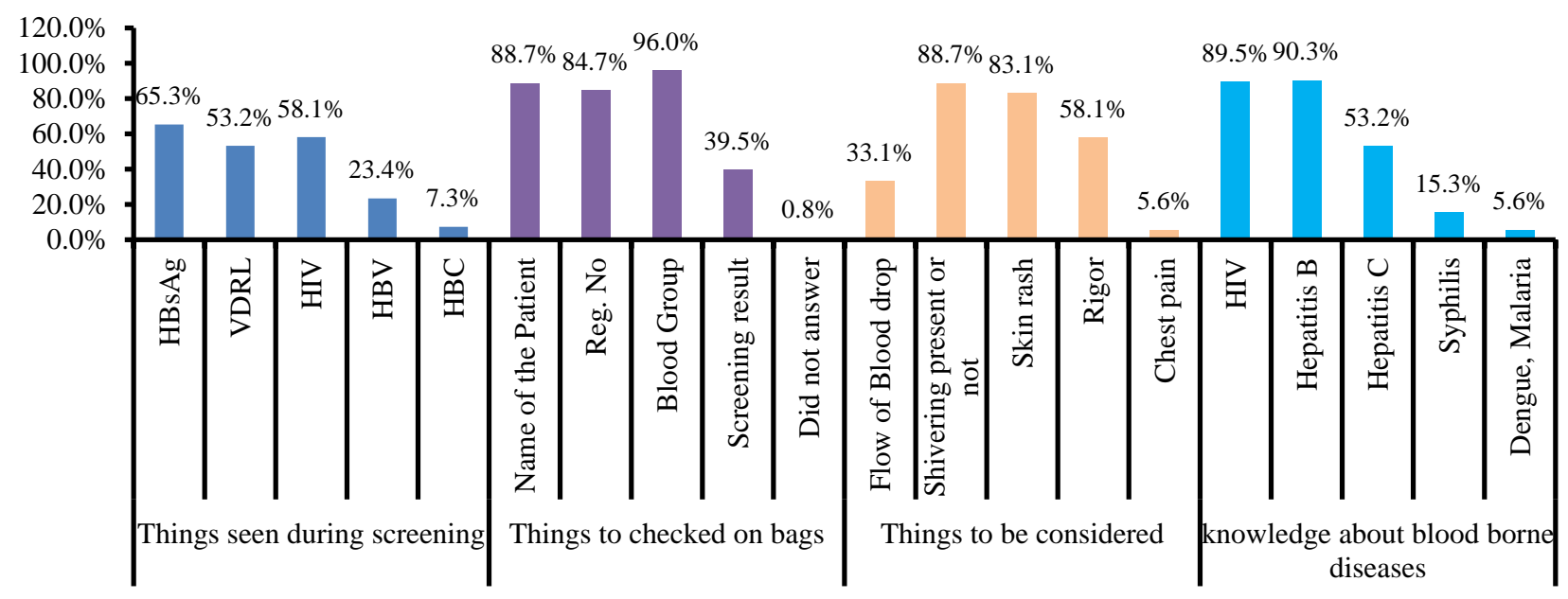

Figure 3. Different things to be considered during to blood transfusion. 
3.4. Respondent's knowledge about preventive measures

Among the respondents almost $48.4 \%$ stated transfuse screened blood as a preventive measure to fix problems regarding blood transfusion. Around 5.6\% of the respondents mentioned maintaining proper system of blood transfusion as a measure. A few respondents comprising almost $4.0 \%$ said that difficulties due to blood transfusion can be prevented by controlling blood transfusion related side effect (Table 2).

Table 2. Respondent's knowledge about preventive measures $(n=124)$.

\begin{tabular}{lll}
\hline Preventive measures & Frequency & Percentage $(\%)$ \\
\hline Transfuse screened Blood & 60 & $48.4 \%$ \\
Maintain proper system of blood transfusion & 7 & $5.6 \%$ \\
Control blood transfusion related side effect & 5 & $4.0 \%$ \\
\hline
\end{tabular}

\subsection{Knowledge on blood transfusion}

The distribution of the respondents having knowledge on blood transfusion is shown Figure 4. More than half of the respondents $(57 \%)$ had moderate knowledge on blood transfusion. This was closely followed by good knowledge level at $41 \%$. The number of respondents having poor knowledge stood at only $2 \%$.

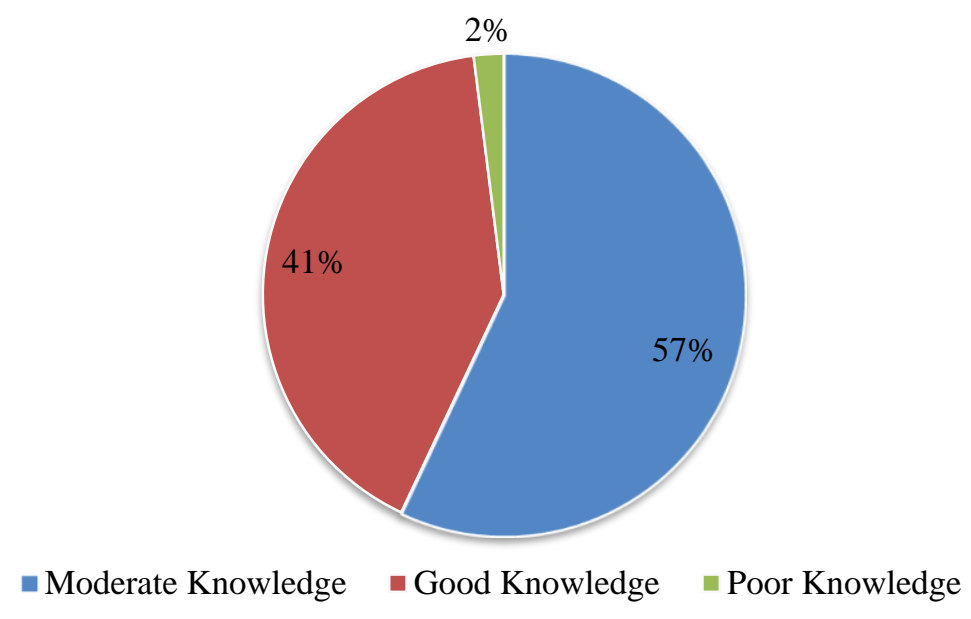

Figure 4. Respondents knowledge on blood transfusion (n=124).

The knowledge level of the respondents on blood transfusion according to year of service was observed in this study; there is an association between knowledge level on blood transfusion and year of service. This association is statistically not significant having p value .074 (Fisher's Exact Test Value 10.60, p=0.074).

\section{Discussion}

This was a cross sectional study and was carried out in Dhaka Medical College Hospital (DMCH) having blood transfusion patients and well organized blood bank. The ages of the respondents were categorized in four different group's ranges from 26-55 years with highest age group in above 40 years. As we observed in this study almost all respondents were female and married (97.6\%). Gerrard (2006); Heddle (2006) observed similar findings.

The level of professional education achieved by the respondents. Interestingly $100 \%$ of the respondents had diploma in nursing. This was closely followed by diploma in midwifery. But it was found in another study that grades of the nursing profession and training in blood transfusion medicine within Europe, most nurses receive pre-registration training in college or university level nursing schools (Saillour-Glenisson et al., 2002; Simmons, 2003).). Two to four years training in the various disciplines of nursing contains a variety of curricula in basic blood transfusion, clinical indications and optimal use of blood products in medical conditions and in surgery (Hewitt, 2005; Aslani et al., 2010).

Post graduate training to promote quality and safety in blood transfusion is usually organized by scientific societies and locally by academic of national health system institutions. In the study a six month training course in a regional blood transfusion center is mandatory in Greece for all nurses and technicians working in a hospital blood bank (Smith et al., 2010; Nurhan et al., 2000). 
Tabiee et al. (2001) stated in their study in Turkey conducted a study; there was a statically significant relation between the experience and knowledge scores, but not between the experience and practice scores, similar findings were observed in this study.

A large number of respondents mentioning HBsAg, VDRL and HIV which is parallel to the Reza et al. (2009). In this study, among the respondents almost all (96\%) said that blood group should be checked on bags before blood is given to patients. Restructuring the pre-registration nurses, education curricula and evaluating and monitoring good transfusion practice of nurses both within the blood establishment and in the hospital should be considered by the national authorities of the member states. For this purpose, cooperation between the health authorities, nursing schools and academic institutions in required (SaillourGlenisson et al., 2002; Murphy et al., 2007). There are several things which need attention during blood transfusion. A significant number of the respondents mentioned that whether shivering is present or not is important to notice during blood transfusion.

This current study found that more than half of the respondents $(57 \%)$ had moderate knowledge on blood transfusion. This was closely followed by good knowledge level at $41 \%$. The number of respondents having poor knowledge stood at only 2\%. Study conducted in Ankara, Turkey found that against a total score of 100 . None of the participating nurses achieved a score of 100, and only a few had scores higher than 50 (Bryan, 2002; Burgmeier, 2002; Mole et al., 2007). There was a statistically significant relation between the experience and knowledge scores, but not between the experience and practice scores. Study by Tabiee $e t$ al. (2001) found the mean score of knowledge as $16.52 \pm 5.3,47.1 \%$ of the samples got the 'weak' grade and $4.8 \%$ gained a good score.

\section{Conclusions}

This study revealed that nurses had moderate knowledge, particularly regarding things to be considered during blood transfusion, which is the most frequent cause of blood transfusion reactions, as well as regarding immunological blood transfusion reactions. The study results emphasize the need for more frequent in-service training for nurses working in hospital. These results may assist with designing educational programs to promote safe blood transfusion in clinical practice. Designing educational programs and ensuring the availability of trained nurses in the clinical area is likely to update the nurses' knowledge and skills.

\section{Conflict of interest}

None to declare.

\section{References}

Aslani Y, S Etemadyfar and K Noryan, 2010. Nurses' knowledge of blood transfusion in medical training centers of Shahrekord University of Medical Science in 2004. Iran. J. Nurs. Midwifery Res., 15: 141-144.

Bryan S, 2002. Hemolytic transfusion reaction: safeguards for practice. J. Perianesth. Nurs., 17: 399-403.

Burgmeier J, 2002. Failure mode and effect analysis: an application in reducing risk in blood transfusion. Jt. Comm. J. Qual. Improv., 28: 331-339.

Gerrard R, 2006. Good practice guidance for the dissemination of patient information leaflets on blood transfusion. Blood Matters. Autumn, 20: 6-7.

Gray A, C Howell and E Pirie, 2005. Improving blood transfusion: a patient-centred approach. Nurs. Stand., 19: $38-42$.

Hainsworth T, 2004. Guidance for preventing errors in administering blood transfusions. Nurs. Times, 100: 45.

Heddle NM, 2006. Evidence-based decision making in transfusion medicine. Vox. Sang., 91: 214-220.

Hewitt PE, 2005. Medicolegal aspects. In Murphy MF, Pamphilon DH (Eds) Practical Transfusion Medicine. Second edition. Blackwell Publishing, Oxford, 274-279.

Labovich TM, 1997. Transfusion therapy: nursing implications. Clin. J. Oncol. Nurs., 1: 61-72.

Mole LJ, G Hogg and S Benvie, 2007. Evaluation of a teaching pack designed for nursing students to acquire the essential knowledge for competent practice in blood transfusion administration. Nurse Educ. Pract.,7: 228-37.

Murphy MF, AC Casbard, S Ballard, IA Shulman, N Heddle, JP Aubuchon, S Wendel, A Thomson, T Hervig, K Downes, PM Carey and WH Dzik, 2007. Prevention of bedside errors in transfusion medicine (PROBETM) study: a cluster-randomized, matched-paired clinical areas trial of a simple intervention to reduce errors in the pretransfusion bedside check. Transfusion, 47: 771-80.

Nurhan B and E Fethiye, 2000. Blood transfusion knowledge and practice among nurses in Turkey. J. Intraven. Nurs., 23: 310-317. 
Nursing and Midwifery Council (NMC), 2005. Guidelines for Records and Record Keeping. NMC, London.

Sackett DL, SE Straus, WS Richardson, W Rosenberg and RB Haynes, 2000. Evidence-based Medicine: How to Practice and Teach EBM. Second edition. Churchill Livingstone, London.

Saillour-Glenisson F, S Tricaud, S Mathoulin-Pelissier, B Bouchon, I Galperine, P Fialon and LR Salmi, 2002. Factors associated with nurses' poor knowledge and practice of transfusion safety procedures in Aquitaine, France. Int. J. Qual. Health Care, 14: 25-32.

Simmons P, 2003. A primer for nurses who administer blood products. Medsurg Nurs., 12: 184-90.

Smith FC, J Donaldson and L Pirie, 2010. Pre-registration adult nurses' knowledge of safe transfusion practice: Results of a 12 month follow-up study. Nurse Educ. Pract., 10: 101-107.

Stainsby D, H Jones, D Asher, C Atterbury, A Boncinelli, L Brant, CE Chapman, K Davison, R Gerrard , A Gray, S Knowles, EM Love, C Milkins, DB McClelland, DR Norfolk, K Soldan, C Taylor, J Revill, LM Williamson and H Cohen, 2006 . Serious hazards of transfusion: a decade of hemovigilance in the UK. Transfus. Med. Rev., 20: 273-282.

Tabiee SH, N Mahboubeh and SAR Jou, 2001. Nurses' knowledge and practice about blood transfusion in Birjand University of Medical Sciences' Hospitals. Journal of Birjand University of Medical Sciences, 8:1316. 